\title{
The Era of E-Cigarettes: A Cross-Sectional Study of Vaping Preferences, Reasons for Use and Withdrawal Symptoms Among Current E-Cigarette Users in the United Arab Emirates
}

\author{
Muna Barakat ${ }^{1}$ (D) - Feras Jirjees ${ }^{2}$ - Ala'a B. Al-Tammemi ${ }^{3} \cdot$ Raja'a Al-Qudah $^{1} \cdot$ Yassen Alfoteih $^{4} \cdot$ Zelal Kharaba $^{5}$. \\ Hala Al-Obaidi ${ }^{4}$
}

Accepted: 25 January 2021 / Published online: 9 February 2021

(C) The Author(s), under exclusive licence to Springer Science+Business Media, LLC part of Springer Nature 2021

\begin{abstract}
Electronic cigarette (E-cig) use has increased substantially among the young population, who adopt using E-cig for various reasons. Our present study aimed to explore vaping preferences and reasons for using E-cig among current users in the United Arab Emirates (UAE) and to assess physical and psychological symptoms experienced while using E-cig during intermittent fasting. A cross-sectional study was conducted from April 23 to May 22, 2020, to solicit responses from current E-cig users in the UAE. Data were collected about sociodemographic profile, tobacco cigarette smoking, vaping preferences, reasons for use, and withdrawal symptoms during fasting in Ramadan. A convenience sample of 591 adult E-cig users were initially recruited, of whom 392 participants with complete responses were included in our analysis. The majority of participants were males $(\mathrm{n}=275,70.2 \%)$ and around $28.6 \%(\mathrm{n}=112)$ were dual users. Vape tank/Box-mod was the most used type of E-cig $(50.3 \%)$. Most of the participants $(n=317 ; 80.9 \%)$ believed that E-cigs are less harmful than tobacco cigarettes. During fasting time, around $46.2 \%(n=181)$ of E-cig users have experienced various physical symptoms, while $51.0 \%(n=200)$ of users have experienced various psychological symptoms. E-cig use is gaining popularity within the UAE after the recent legalization as these devices are commonly advertised and claimed by manufacturers to aid smoking cessation. The effectiveness of E-cig in aiding smoking cessation should be investigated with a higher level of evidence, especially in a new context of usage as the UAE, considering various types of devices, hundreds of E-liquid brands, and the influence of concurrent poly-tobacco use.
\end{abstract}

Keywords Electronic cigarettes $\cdot$ United Arab Emirates $\cdot$ Withdrawal symptoms $\cdot$ Vaping preferences $\cdot$ Fasting

\section{Introduction}

Muna Barakat and Feras Jirjees contributed equally to this work.

Muna Barakat

m_barakat@asu.edu.jo

1 Faculty of Pharmacy, Applied Science Private University, Amman 11931, Jordan

2 College of Pharmacy, University of Sharjah, 27272 Sharjah, United Arab Emirates

3 Doctoral School of Health Sciences, University of Debrecen, H-4032, Debrecen, Hungary

4 City University College of Ajman, 18484 Ajman, United Arab Emirates

5 College of Pharmacy, Al Ain University, 112612 Abu Dhabi Campus, United Arab Emirates
The World Health Organization (WHO) has declared tobacco smoking as one of the leading causes of morbidity and mortality worldwide [1], with a global number of tobacco smokers exceeded one billion smokers [1,2]. More than $80 \%$ of the world's tobacco smokers reside in low- and middle-income countries, where most tobacco-related morbidity and mortality also occur [1]. Despite that number of smokers is declining in some WHO regions, this is not the case in the Eastern Mediterranean Region (EMR), where the number of smokers is still rising at an alerting trend during the last two decades [2,3]. For instance, many countries in the EMR region have higher records of smoking prevalence per day than the global average by $25 \%$ according to the age-standardized prevalence of daily smoking, such as Egypt, Jordan, Lebanon, Tunisia, and Turkey [2]. In the aforementioned countries, a significant number of 
people commonly use various forms of smoking including conventional/combustible cigarettes, waterpipe/hookah, and recently Electronic cigarettes (E-cig) [1-4].

E-cig is defined as a battery-powered device that heats a liquid (commonly referred to as E-liquid or E-Juice) to produce aerosols to be inhaled by users; thus, imitating the act of conventional smoking [5]. Popularly, E-cig users are called vapers and the process of using an E-cig is called vaping. From a chemical perspective, the E-liquid is mainly composed of solvents (glycerin, propylene glycol), nicotine, and flavoring chemicals [5], although nicotine-free and unflavored E-liquids are also available in the global markets. The presence of nicotine in the E-liquid makes it addictive with psychoactive effects on users [6]. However, the safety of E-cigs is still uncertain and considered a global concern among the scientific community with many debates [6-8].

E-cig manufacturers and merchants advertise and promote it as a less harmful product compared to tobacco, due to the absence of many detrimental toxic substances that present in conventional/combustible tobacco products [9]. Also, some studies have demonstrated the ability of E-cig to be used as a tool for tobacco smoking cessation [10]. On the other hand, the long-term outcomes of exposure to E-cig is a public health concern for both, the public health decisionmakers and health practitioners [6].

Ramadan is a holy month when Muslims refrain from food, fluids, and smoking for around $16 \mathrm{~h}$ per day (total fasting hours in a day depends on sunrise and sunset times in different countries). During this month, many smokers invest in these religious moments and think about smoking cessation. As well, experts thought that Ramadan could be an ideal time to get rid of harmful addictions such as smoking $[11,12]$. However, during fasting time, smokers find it far easier to abstain from food and water than to quit smoking [11]. Thus, quitting an addictive substance (i.e., nicotine) is not an easy task due to withdrawal symptoms. Part of these withdrawal symptoms are manageable, while others can affect daily life and psychological health $[13,14]$.

The United Arab Emirates (UAE) is a country in Western Asia at the northeast end of the Arabian Peninsula, and Islam is the official religion of the country. In 2017, the UAE population was estimated to be 9.3 million, of which $15 \%$ were Emirati citizens. More than 200 nationalities are living and working in the country [15]. In the UAE, the prevalence of tobacco smoking is $15.4 \%$ among males (above 15 years old) and 2.4\% among females (above 15 years old) [16]. Besides, a considerable number of smokers in the UAE use different sources of nicotine such as tobacco cigarettes, waterpipe/hookah, and Midwakh (a tobacco blend that is smoked using a small pipe of Arabian origin, popularly in the UAE) [17].

There are many regulations to counter smoking in the UAE such as high tobacco tax, restriction in licensing tobacco retailers, and banned smoking areas [18]. In contrary to tobacco smoking, the E-cig use among the UAE population was not well addressed in the literature. Therefore, our present study aimed (i) to explore vaping preferences and reasons for using E-cig among current users/vapers in the UAE and, (ii) to assess the experienced physiological and psychological withdrawal symptoms among E-cig users during fasting time in the holy month of Ramadan.

\section{Methods and Materials}

\section{Study Design and Participants}

This study has adopted a descriptive cross-sectional design. Data were collected using an anonymous web-based survey during the second week of Ramadan (April 23-May 22,2020 ). A self-administered questionnaire was distributed using a convenience sampling technique. Eligible participants should have met all the following criteria, including the age of 18 years or older, current E-cig user, living in the UAE, and have experienced intermittent fasting in Ramadan. These conditions were explained to participants in the introductory page of our survey. Participants were recruited through advertising our study on different social media platforms including Facebook ${ }^{\circledR}$, WhatsApp ${ }^{\circledR}$, LinkedIn $®$, and Twitter®. Participants were also informed that their participation in the study is voluntary and has no risks. Participants who completed the questionnaire have given informed consent by declaring their eligibility and accepting to fill out the questionnaire. Ethical approval for our study was obtained from the Research Ethics Committee, University of Sharjah (Approval number: REC-20-07-30-01).

\section{Survey Instrument}

A structured questionnaire was developed by the authors after a careful and extensive review of related literature, utilizing the general principles of good survey design [18-21]. The questionnaire was distributed to participants in both Arabic and English versions using Google Form (A secure web-based survey tool provided by Google $($ ). Both languages were used due to the diversity of the UAE population (nationals and expatriates).

After the initial development of our questionnaire, it was evaluated by three experts in the field for content and face validity. The questions were made free of medical jargon or difficult terminology. The questionnaire was developed in English, then was translated into Arabic using translation and back-translation technique by two independent academic translators. Also, to ensure clarity, readability, and understandability, the questionnaire was piloted (in both languages) on 15 E-cig users, and refinements were made 
as needed. To help participants report accurate data related to the type of E-cig device they are using, popular types/ designs of E-cig devices were graphically demonstrated in the questionnaire in form of images.

The survey questionnaire consisted of 23 multiple-choice questions that can be completed within an average time of $10 \mathrm{~min}$. The questionnaire consisted of four sections. The first section solicited sociodemographic information including age, gender, marital status, ethnicity, educational level, occupation, whether having children at house or not, and the number of caffeinated beverages taken per day. The second section assessed the tobacco cigarette smoking status of study participants (never smoker, current smoker, and former smoker), duration of current or former cigarette smoking, and frequency of current tobacco cigarette smoking. The third section gathered basic information related to E-cig use and vaping preferences including design of E-cig device used by participants, the nicotine concentration of E-liquid, duration of E-cig use, daily E-liquid consumption (estimated in milliliters used), driving reasons for using E-cig, and E-cig quit attempts during the month of Ramadan. In addition, we asked the participants to report the main driving hit of E-liquid used (propylene glycol, vegetable glycerin, a mix of both, I do not know). The fourth section of our questionnaire assessed E-cig users' withdrawal symptoms during fasting in Ramadan. Participants were given a list of 11 physical symptoms and 8 psychological symptoms. Each symptom had two response choices, either yes/present or no/absent. Each physical and psychological symptom was scored based on whether it was present (score of 1) or absent (score of 0 ); thus, the overall physical symptoms' score ranges between ( 0 and 11$)$, while the overall psychological symptoms' score ranges between ( 0 and 8$)$. There were no cut-off scores implemented, that is, a higher score in each category (physical, psychological) represents higher withdrawal symptoms in the same category.

Also, in the fourth section, participants were asked to report how they managed these withdrawal symptoms during fasting, the duration of abstinence from E-cig use to the moment of experiencing withdrawal symptoms during fasting (measured in hours), and lastly to self-report the overall intensity/severity of withdrawal symptoms as perceived (on a scale from 0 to 5). Concerning the internal consistency of the withdrawal symptoms' scale, the Cronbach alpha for physical and psychological withdrawal scales was found to be 0.87 and 0.88 , respectively.

\section{Sample Size}

As E-cig use was recently legalized in the UAE (April 2019) [22], there is no published data regarding E-cig users yet. Therefore, the target sample size was estimated based on the Raosoft ${ }^{\circledR}$ software sample size calculator for the minimal sample size needed for unlimited population size using a confidence level of $95 \%$, a standard deviation of 0.5 , a margin of error of 5\%, thus, the required sample size was estimated to be at least 385 participants.

\section{Data Analyses}

Completed responses were extracted from Google Form ${ }^{\circledR}$ as an Excel sheet for quality check and then exported into Statistical Package for Social Sciences version 24.0 (SPSS Inc., Armonk, NY: IBM Corp, USA) for statistical analyses. Descriptive statistics including mean, standard deviation (SD), frequency, and proportions were calculated and reported as appropriate. Chi-square test was used to compare E-cig users by their tobacco cigarette smoking status and sociodemographic characteristics. Mean $( \pm S D)$ of overall withdrawal symptoms was also calculated for both physical and psychological symptoms and were compared by tobacco cigarette smoking status using the Kruskal-Wallis test. A P value of $<0.05$ represented a statistically significant difference.

\section{Results}

\section{Sociodemographic Characteristics of Participants}

The total number of received responses in our study was 591. After the exclusion of incomplete ones, a total of $\mathbf{3 9 2}$ valid and complete responses remained and were included in the final analysis. Almost half of the participants were less than 25 years old $(n=198,50.5 \%)$, and males have predominated the sample $(n=275,70.2 \%)$. Most of participants were Arabs $(n=331,84.4 \%)$, had a bachelor's degree $(n=256$; $65.3 \%)$, were single $(n=210,53.6 \%)$, did not have children $(\mathrm{n}=262,66.9 \%)$. Moreover, the majority of the participants $(n=342 ; 87.2 \%)$ used to drink caffeinated beverages on daily basis, of whom $(n=198,50.5 \%)$ used to drink $2-3$ caffeinated drinks per day. See Table 1 for more details.

\section{Tobacco Cigarette Smoking Status Among Participants.}

Based on tobacco cigarette smoking status, respondents were classified into exclusive E-cig users who never smoked tobacco cigarettes $(n=95,24.2 \%)$, exclusive E-cig users who were former cigarette smokers $(n=185,47.2 \%)$, and those who currently vape and smoke tobacco cigarettes or so-called dual users $(n=112,28.6 \%)$. Table 1 illustrates the sociodemographic characteristics of E-cig users categorized by their tobacco cigarette smoking status. Also, out of 112 dual users, 58 and 15 participants were found to have moderate and high tobacco cigarette consumption per day (10-20 
Table 1 Sociodemographic characteristics of Study Participants (E-cig users) categorized by their Tobacco Cigarette Smoking Status $(\mathrm{n}=392)$

\begin{tabular}{|c|c|c|c|c|c|}
\hline \multirow[t]{2}{*}{ Characteristic } & \multicolumn{4}{|l|}{$\mathrm{n}(\%)$} & \multirow{2}{*}{$\begin{array}{l}P \\
\text { value* }\end{array}$} \\
\hline & $\begin{array}{l}\text { Never smoker } \\
(\mathrm{n}=95)\end{array}$ & $\begin{array}{l}\text { Former } \\
\text { smoker } \\
(n=185)\end{array}$ & $\begin{array}{l}\text { Current } \\
\text { smoker } \\
(\mathrm{n}=112)\end{array}$ & Total $(n=392)$ & \\
\hline \multicolumn{5}{|l|}{ Age (years) } & $<0.001$ \\
\hline $18-25$ & $65(16.6)$ & $70(17.9)$ & $63(16.1)$ & $198(50.5)$ & \\
\hline $26-40$ & $30(7.7)$ & $99(25.3)$ & $40(10.2)$ & $169(43.1)$ & \\
\hline $40-55$ & $0(0.0)$ & $16(4.1)$ & $9(2.3)$ & $25(6.4)$ & \\
\hline \multicolumn{5}{|l|}{ Gender } & 0.815 \\
\hline Male & $68(17.3)$ & $131(33.4)$ & $76(19.4)$ & $275(70.2)$ & \\
\hline Female & $27(6.9)$ & $54(13.8)$ & $36(9.2)$ & $117(29.8)$ & \\
\hline \multicolumn{5}{|l|}{ Ethnicity } & 0.124 \\
\hline Arab & $74(18.9)$ & $161(41.1)$ & $96(24.5)$ & $331(84.4)$ & \\
\hline Non-Arab & $21(5.4)$ & $24(6.1)$ & $16(4.1)$ & $61(15.6)$ & \\
\hline \multicolumn{5}{|l|}{ Education } & $<0.001$ \\
\hline No degree & $27(6.9)$ & $3(0.8)$ & $8(2.0)$ & $38(9.7)$ & \\
\hline Secondary school & $11(2.8)$ & $8(2.0)$ & $8(2.0)$ & $27(6.9)$ & \\
\hline Diploma & $4(1.0)$ & $13(3.3)$ & $18(4.6)$ & $35(8.9)$ & \\
\hline Bachelor's Degree & $49(12.5)$ & $139(35.5)$ & $68(17.3)$ & $256(65.3)$ & \\
\hline Postgraduate Degree & $4(1.0)$ & $22(5.6)$ & $10(2.6)$ & $36(9.2)$ & \\
\hline \multicolumn{5}{|l|}{ Occupation } & $<0.001$ \\
\hline University student & $45(11.5)$ & $11(2.8)$ & $21(5.4)$ & 77 (19.6) & \\
\hline Employee/health sector & $13(3.3)$ & 69 (17.6) & $21(5.4)$ & $103(26.3)$ & \\
\hline Employee/non-health sector & $28(7.1)$ & $76(19.4)$ & $51(13.0)$ & $155(39.5)$ & \\
\hline Unemployed/retired & $8(2.0)$ & $27(6.9)$ & $15(3.8)$ & $50(12.8)$ & \\
\hline Others & $1(0.3)$ & $2(0.5)$ & $4(1.0)$ & $7(1.8)$ & \\
\hline \multicolumn{5}{|l|}{ Marital status } & $<0.001$ \\
\hline Married & $26(6.6)$ & $107(27.3)$ & $31(7.9)$ & $164(41.8)$ & \\
\hline Single & $68(17.3)$ & $68(17.3)$ & $74(18.9)$ & $210(53.6)$ & \\
\hline Divorced/widowed & $1(0.3)$ & $10(2.6)$ & $7(1.8)$ & $18(4.6)$ & \\
\hline \multicolumn{5}{|l|}{ Having children } & $<0.001$ \\
\hline Yes & $10(2.6)$ & $90(23.0)$ & $30(7.7)$ & $130(33.2)$ & \\
\hline No & $17(4.3)$ & $27(6.9)$ & $8(2.0)$ & $52(13.3)$ & \\
\hline Single (no children) & $68(17.3)$ & $68(17.3)$ & $74(18.9)$ & $210(53.6)$ & \\
\hline \multicolumn{5}{|c|}{ No. of caffeinated beverages per day } & 0.280 \\
\hline None & $13(3.3)$ & $25(6.4)$ & $12(3.1)$ & $50(12.8)$ & \\
\hline One drink & $14(3.6)$ & $36(9.2)$ & 27 (6.9) & 77 (19.6) & \\
\hline $2-3$ drinks & $50(12.8)$ & $87(22.2)$ & $61(15.6)$ & $198(50.5)$ & \\
\hline$\geq 4$ drinks & $18(4.6)$ & $37(9.4)$ & $12(3.1)$ & $67(17.1)$ & \\
\hline
\end{tabular}

All percentages were calculated based on the total sample $(\mathrm{n}=392)$

${ }^{*}$ Chi-square test (significance at $P$ value $<0.05$ ) and $>20$ cigarettes per day, respectively). Besides, around half of dual users were smoking tobacco cigarettes for more than 5 years.

\section{Vaping Preferences and Reasons for Use}

Regarding E-cig device's design (generation), the most used vaping devices were vaping tanks/box-mod $(50.3 \%)$ which represents the third generation of E-cig devices, followed by vape pod $(26.0 \%)$, which represents the fourth generation of E-cig devices (this type of device uses higher nicotine concentrations in their E-liquid, usually as nicotine salts, compared to previous generations). See Fig. 1.

The majority of participants in our study $(n=275,70.2 \%)$ have been using E-cig for a period of less than 1 year, while the rest $(n=117,29.8 \%)$ were using E-cig for more than a year. Participants have also reported the nicotine concentration they most commonly used in the E-liquid. Only 44 
Fig. 1 Types of E-cig devices that were used by the study participants $(n=392)$

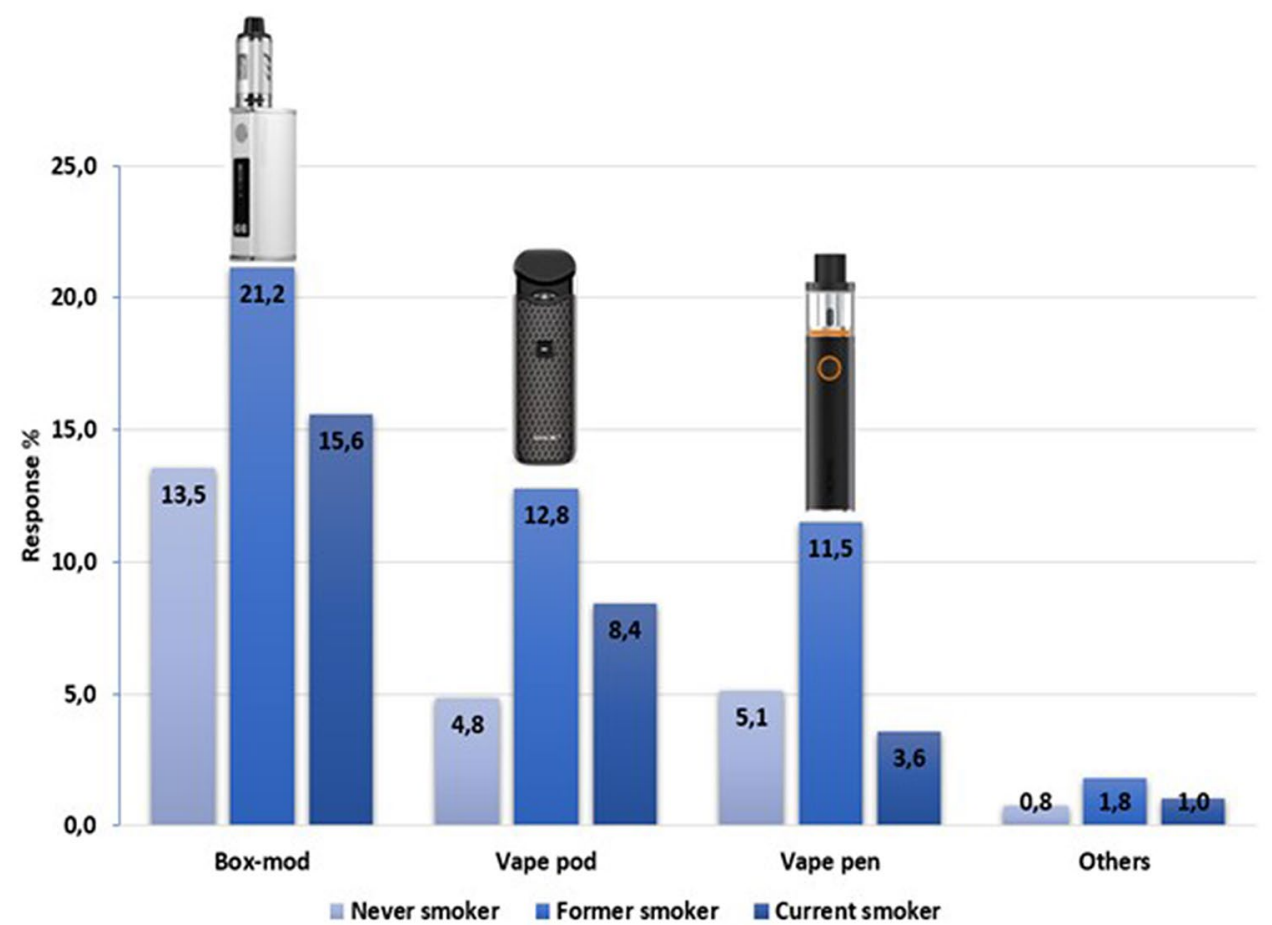

E-cig users (11.2\%) reported using nicotine-free E-liquids, whereas most E-cig users $(n=232,59.2 \%)$ used an E-liquid with nicotine concentration in the range $(1-10 \mathrm{mg} / \mathrm{mL})$. Around $(n=53,13.5 \%)$ have reported using higher levels of nicotine concentrations ( $>30 \mathrm{mg} / \mathrm{mL}$ ).

Regarding E-liquid consumption, most participants $(\mathrm{n}=253 ; 64.5 \%)$ have consumed $2-5 \mathrm{~mL}$ of E-liquid per day, and only 50 users $(12.8 \%$ ) consumed more than $5 \mathrm{~mL}$ of E-liquid per day. Moreover, around 52.0\% ( $n=204)$ of E-cig users reported that the preferred vehicle of their E-liquid was a mixture of both propylene glycol and vegetable glycerin. See Table 2 for more details regarding vaping preferences of E-cig users, categorized by their tobacco cigarette smoking status.

Moreover, participants were asked to report the reasons for using E-cig. They could have chosen all that applied to their situation from a list of reasons provided to them. Most of the participants $(n=317 ; 80.9 \%)$ believed that E-cigs are less harmful than tobacco cigarettes while 282 participants (71.9\%) reported that they use E-cig to help them quit smoking tobacco cigarettes smoking. Moreover, other reasons for using use E-cig were to try new types of smoking and flavors /curiosity $(\mathrm{n}=185,47.2 \%)$, a sort of modernization/for socializing $(n=150,38.3 \%)$.

\section{Withdrawal Symptoms During Fasting in Ramadan}

During fasting time, most E-cig users reported no physical symptoms due to abstinence from using E-cig $(n=211$, $53.8 \%$ ), while around $46.2 \%$ of E-cig users have experienced various physical symptoms. Breathing difficulties, sore/itchy throat, and nausea were the most reported symptoms among $28.1 \%, 22.2 \%$, and $21.9 \%$ of the overall cohort, respectively. The mean $\left(_{M}\right)$ of physical withdrawal symptoms score was the highest among dual users $\left({ }_{M} 1.60, S_{\text {SD: }} 2.20\right)$ and the lowest among E-cig users who were never tobacco smokers ${ }_{M} 1.34$, SD: 1.78). However, the differences in mean scores of physical withdrawal symptoms among different categories of E-cig users (never smokers, former smokers, and dual users) were statistically not significant as revealed by the Kruskal-Wallis test $(P$ value $=0.199)$. See Table 3 for details.

In addition to physical symptoms, $51.0 \%$ of participants have experienced various psychological symptoms, with an intense craving for vaping $(\mathrm{n}=198,50.4 \%)$, restlessness $(n=135,34.4 \%)$, and poor concentration $(n=99,25.2 \%)$ were the most experienced symptoms among study participants in general. In parallel to the physical symptoms scale, the mean $\left(_{M}\right)$ score of psychological withdrawal symptoms scale was the highest among dual users $\left({ }_{M} 1.92\right.$, SD: 2.24$)$, and the lowest among never smokers E-cig users $\left(_{M} 1.48\right.$, $\mathrm{SD}: 1.92)$. Also, the differences in mean scores between the three categories of E-cig users were statistically not significant $(\mathrm{P}$ value $=0.052)$. See Table 3 .

\section{Perceived Severity of Symptoms and Quit Attempts}

E-cig users were asked to report self-perceived severity of withdrawal symptoms (ranging from weak to very severe) experienced during fasting in Ramadan. Of those who ever 
Table 2 Descriptive Data about E-cig usage among the Study Participants, categorized by users' Tobacco Cigarette Smoking Status $(\mathrm{n}=392)$

\begin{tabular}{|c|c|c|c|c|}
\hline \multirow[t]{2}{*}{ Vaping preferences } & \multicolumn{3}{|l|}{$\mathrm{n}(\%)$} & \multirow[b]{2}{*}{$\begin{array}{l}\text { Total } \\
(\mathrm{n}=392)\end{array}$} \\
\hline & $\begin{array}{l}\text { Never smoker } \\
(\mathrm{n}=95)\end{array}$ & $\begin{array}{l}\text { Former smoker } \\
(\mathrm{n}=185)\end{array}$ & $\begin{array}{l}\text { Current smoker } \\
(\mathrm{n}=112)\end{array}$ & \\
\hline \multicolumn{5}{|l|}{ Duration of using E-Cig (years) } \\
\hline$<1$ year & $65(16.6)$ & $136(34.7)$ & $74(18.9)$ & $275(70.2)$ \\
\hline $1-3$ year & $28(7.1)$ & $38(9.7)$ & $35(8.9)$ & $101(25.8)$ \\
\hline $3-5$ years & $2(0.5)$ & $11(2.8)$ & $3(0.8)$ & $16(4.1)$ \\
\hline \multicolumn{5}{|l|}{ Nicotine concentration of E-liquid } \\
\hline Zero nicotine & $18(4.6)$ & $16(4.1)$ & $10(2.6)$ & $44(11.2)$ \\
\hline $1-10 \mathrm{mg} / \mathrm{mL}$ & $51(13.0)$ & $118(30.1)$ & $63(16.1)$ & $232(59.2)$ \\
\hline $11-20 \mathrm{mg} / \mathrm{mL}$ & $7(1.8)$ & $16(4.1)$ & $12(3.1)$ & $35(9.0)$ \\
\hline $21-30 \mathrm{mg} / \mathrm{mL}$ & $6(1.5)$ & $10(2.6)$ & $12(3.1)$ & $28(7.1)$ \\
\hline$>30 \mathrm{mg} / \mathrm{mL}$ & $13(3.3)$ & $25(6.4)$ & $15(3.8)$ & $53(13.5)$ \\
\hline \multicolumn{5}{|l|}{ Volume of consumed E-liquid per day } \\
\hline Less than $2 \mathrm{~mL}$ & $24(6.1)$ & $44(11.2)$ & $21(5.4)$ & $89(22.7)$ \\
\hline $2-5 \mathrm{~mL}$ & $59(15.1)$ & $116(29.6)$ & $78(19.9)$ & $253(64.5)$ \\
\hline More than $5 \mathrm{~mL}$ & $12(3.1)$ & $25(6.4)$ & $13(3.3)$ & $50(12.8)$ \\
\hline \multicolumn{5}{|l|}{ Vehicle of E-liquid } \\
\hline $\begin{array}{l}\text { Mixture of propylene glycol and } \\
\text { vegetable glycerin }\end{array}$ & $39(9.9)$ & $90(23.0)$ & $75(19.1)$ & $204(52.0)$ \\
\hline Propylene glycol alone & $4(1.0)$ & $6(1.5)$ & $4(1.0)$ & $14(3.6)$ \\
\hline Vegetable glycerin alone & $5(1.3)$ & $8(2.0)$ & 0 & $13(3.3)$ \\
\hline Do not know & 47 (12.0) & $81(20.7)$ & $33(8.4)$ & 161 (41.1) \\
\hline
\end{tabular}

All percentages were calculated based on the total sample $(n=392)$ experienced any withdrawal symptoms (described in the previous section), 103 E-cig users rated their symptoms as weak, followed by mild to moderate level of severity as perceived by another $97 \mathrm{E}$-cig users. Interestingly, no one has rated the perceived symptoms as severe or very severe. Table 4 describes more details. Moreover, the onset of withdrawal symptoms has varied between E-cig users. Around $41.3 \%$ of E-cig users had their withdrawal symptoms started after $12 \mathrm{~h}$ of abstinence from vaping. See Table 4.

The main way to control withdrawal symptoms among participants was keeping themselves busy $(\mathrm{n}=246,62.7 \%)$, followed by consulting a healthcare provider $(\mathrm{n}=99$, $25.2 \%)$. Only $9.2 \%$ of users $(n=36)$ reported using Nicotine Replacement Therapy (NRT) in form of a nicotine patch to relieve withdrawal symptoms during fasting. See Fig. 2. Furthermore, around a quarter of E-cig users in our study disclosed they tried to quit using E-cig during Ramadan, and of those who tried, $79.6 \%$ have confirmed their success. See Fig. 3.

\section{Discussion}

Smoking is considered one of the main risk factors for many diseases worldwide [19]. In literature, there are pieces of evidence that many tobacco smokers have a willingness to quit $[20,21]$. However, smoking cessation is sought to be quite difficult with frequent relapses amongst those who try to quit, mainly due to withdrawal symptoms [22, 23]. In our study, most E-cig users were found to be either former tobacco cigarette smokers or current tobacco cigarette smokers. Most of them have experienced relatively weak E-cig withdrawal symptoms during fasting time in Ramadan as well. Around a quarter of E-cig users in our study have used the vape pod E-cig, which possesses a high nicotine concentration in its E-liquid. Although E-cig has been used as an alternative tool among tobacco smokers because it is often promoted as a safer replacement for traditional smoking, the safety of E-cig is still debatable with some shreds of evidence about the chronic exposure to E-cig vapor which could alter the physiology of lung epithelium and compromise the immune system [24].

In our present study, most E-cig users were 40 years of age or less (93.6\%). In a study published in 2011 in the UAE, the mean age for tobacco smokers among UAE nationals was 32.8 years [25]. Besides, Al-Mulla and his team had reported an increased rate of tobacco used among school students aged 13-15 compared to adults in the UAE [26]. Also, most E-cig users in our study (87.2\%) have reported drinking at least one caffeinated beverage per day, and this is in agreement with published literature that showed smokers 
Table 3 Frequency of Withdrawal Symptoms Experienced by E-cig users During Fasting Time in Ramadan

\begin{tabular}{|c|c|c|c|c|c|}
\hline & \multicolumn{4}{|l|}{$\mathrm{n}(\%)$} & \multirow[t]{2}{*}{$P$ value $^{+}$} \\
\hline & Never smoker $(n=95)$ & Former smoker $(n=185)$ & Current smoker $(\mathrm{n}=112)$ & Total $(n=392)$ & \\
\hline \multicolumn{6}{|l|}{ Physical symptoms } \\
\hline Weight gain & $2(0.5)$ & $12(3.1)$ & $5(1.3)$ & $19(4.8)$ & 0.131 \\
\hline Sweating & $4(1.0)$ & $8(2.0)$ & $7(1.8)$ & $19(4.8)$ & 0.870 \\
\hline Abdominal cramping & $2(0.5)$ & $9(2.3)$ & $5(1.3)$ & $16(4.1)$ & 0.655 \\
\hline Tremor & $5(1.3)$ & $9(2.3)$ & $7(1.8)$ & $21(5.4)$ & 0.606 \\
\hline Breathing difficulty & $30(7.7)$ & $54(13.8)$ & $26(6.6)$ & $110(28.1)$ & 0.589 \\
\hline Constipation & $9(2.3)$ & $27(6.9)$ & $23(5.9)$ & $59(15.1)$ & 0.202 \\
\hline Sore or itchy throat & $17(4.3)$ & $43(11.0)$ & $27(6.9)$ & $87(22.2)$ & 0.489 \\
\hline Heart palpitation & $20(5.1)$ & $35(8.9)$ & $20(5.1)$ & $75(19.1)$ & 0.251 \\
\hline Dizziness & $11(2.8)$ & $20(5.1)$ & $16(4.1)$ & $47(12.0)$ & 0.645 \\
\hline Headache & $11(2.8)$ & $20(5.1)$ & $16(4.1)$ & $47(12.0)$ & 0.645 \\
\hline Nausea & $16(4.1)$ & $43(11.0)$ & $27(6.9)$ & $86(21.9)$ & 0.729 \\
\hline No symptoms & $50(12.8)$ & $101(25.8)$ & $60(15.3)$ & $211(53.8)$ & 0.049 \\
\hline $\begin{array}{l}\text { Physical score } \\
\text { Mean }( \pm S D)\end{array}$ & $1.34( \pm 1.78)$ & $1.51( \pm 2.06)$ & $1.60( \pm 2.20)$ & $1.48( \pm 2.01)$ & $0.199^{\$}$ \\
\hline \multicolumn{6}{|l|}{ Psychological symptoms } \\
\hline Social isolation & $6(1.5)$ & $10(2.6)$ & $5(1.3)$ & $21(5.3)$ & 0.958 \\
\hline Depression & $6(1.5)$ & $14(3.6)$ & $5(1.3)$ & $25(6.4)$ & 0.768 \\
\hline Feeling sleepy & $11(2.8)$ & $40(10.2)$ & $23(5.9)$ & $74(18.8)$ & 0.289 \\
\hline Poor concentration & $17(4.3)$ & $47(12.0)$ & $35(8.9)$ & $99(25.2)$ & 0.050 \\
\hline Angry & $12(3.1)$ & $42(10.7)$ & $24(6.1)$ & $78(19.9)$ & 0.166 \\
\hline Stress & $12(3.1)$ & $42(10.7)$ & $42(10.7)$ & $96(24.5)$ & 0.269 \\
\hline Restlessness & $30(7.7)$ & $63(16.1)$ & $42(10.7)$ & $135(34.4)$ & 0.709 \\
\hline Intense cravings for vaping & $47(12.0)$ & $90(23.0)$ & $61(15.6)$ & $198(50.4)$ & 0.335 \\
\hline No symptoms & $51(13.0)$ & $90(23.0)$ & $51(13.0)$ & $192(49.0)$ & 0.048 \\
\hline $\begin{array}{l}\text { Psychological score } \\
\text { Mean }( \pm S D)\end{array}$ & $1.48( \pm 1.92)$ & $1.88( \pm 2.35)$ & $1.92( \pm 2.24)$ & $1.76( \pm 2.16)$ & $0.052^{\$}$ \\
\hline
\end{tabular}

Participants were able to choose multiple symptoms that applied to their situation $(n=392)$

All percentages were calculated based on the total sample $(\mathrm{n}=392)$

${ }^{+}$Chi-square test (significance at $P$ value $<0.05$ )

${ }^{\$}$ Kruskal-Wallis test was used to compare scores between tobacco cigarette smoking groups

are coffee drinkers, as these behaviors often occur concurrently $[27,28]$.

Concerning health, most E-cig users in our study thought that vaping is safer than combustible tobacco products and believed that it could aid smoking cessation. Shifting towards E-cig as an alternative to conventional smoking could be reasoned by the level of awareness among tobacco users. The WHO has declared in one of the reports that the majority of tobacco users seem to be convinced to quit smoking when they become aware of the full range of harmful consequences that results from smoking and the health benefits of smoking cessation [29]. This is also consistent with the findings of our study as most of the participants in our study $(n=297,75.8 \%)$ were either former tobacco smokers or current tobacco smokers (dual users), and this strengthens the assumption that traditional tobacco smokers try to find alternative smoking habits, especially that many countries including the UAE have many regulations to control nicotine use [18].

Several published studies have been conducted to evaluate the beliefs and attitudes toward E-cig [30-33]. In contrary to our results, in Dwedar et al.'s study [30], most health care providers believed that E-cig was unsafe and did not help in smoking cessation, while Tamimi's study [31] reported that many E-cig users approached it as a therapeutic aid to stop or cut down tobacco smoking, despite that some of the participants used E-cig as a hobby and a social activity [31]. These contradictions in results between these studies and our study might be attributed to the different target population that has been studied. Moreover, another study indicated that current tobacco smokers with quitting experience were more likely aware of and willing to use E-cig than current 
Table 4 Self-reported Severity Perception and Onset of E-cig Withdrawal Symptoms among Participants $(n=392)$

\begin{tabular}{|c|c|c|c|c|}
\hline \multirow[t]{2}{*}{ Domain } & \multicolumn{4}{|l|}{$\mathrm{n}(\%)$} \\
\hline & $\begin{array}{l}\text { Never smoker } \\
(\mathrm{n}=95)\end{array}$ & $\begin{array}{l}\text { Former smoker } \\
(\mathrm{n}=185)\end{array}$ & $\begin{array}{l}\text { Current smoker } \\
(\mathrm{n}=112)\end{array}$ & Total $(n=392)$ \\
\hline \multicolumn{5}{|c|}{ Severity of withdrawal symptoms (severity range $0-5$ ) } \\
\hline No symptoms $($ score $=0$ ) & $51(13.0)$ & $90(23.0)$ & $51(13.0)$ & $192(49.0)$ \\
\hline Weak $($ score $=1)$ & $28(7.1)$ & $40(10.2)$ & $35(8.9)$ & $103(26.3)$ \\
\hline Mild (score $=2$ ) & $16(4.1)$ & $32(8.2)$ & $14(3.6)$ & $62(15.8)$ \\
\hline Moderate $($ score $=3$ ) & $0(0.0)$ & $23(5.9)$ & $12(3.1)$ & $35(8.9)$ \\
\hline Severe $($ score $=4)$ & $0(0.0)$ & $0(0.0)$ & $0(0.0)$ & $0(0.0)$ \\
\hline Very severe $($ score $=5)$ & $0(0.0)$ & $0(0.0)$ & $0(0.0)$ & $0(0.0)$ \\
\hline \multicolumn{5}{|c|}{ Onset of withdrawal symptoms from the last E-cigarette use } \\
\hline No symptoms & $51(13.0)$ & $90(23.0)$ & $51(13.0)$ & $192(49.0)$ \\
\hline Less than $6 \mathrm{~h}$ & $1(0.3)$ & $0(0.0)$ & $0(0.0)$ & $1(0.3)$ \\
\hline After $6 \mathrm{~h}$ & $4(1.0)$ & $4(1.0)$ & $2(0.5)$ & $10(2.6)$ \\
\hline After $8 \mathrm{~h}$ & $3(0.8)$ & $10(2.6)$ & $14(3.6)$ & 27 (6.9) \\
\hline After $12 \mathrm{~h}$ & $6(1.5)$ & 18 (4.6) & $23(5.9)$ & $47(12.0)$ \\
\hline After more than $16 \mathrm{~h}$ & $34(8.7)$ & $49(12.5)$ & $32(8.2)$ & $115(29.3)$ \\
\hline
\end{tabular}

All percentages were calculated based on the total sample $(n=392)$

\section{Keeping myself busy to tolerate the withdrawal symptoms \\ Taking an advice (counseling) from a pharmacist or medical practitioner}

Getting back to tobacco smoking instead of E-cig

Taking medications to manage the symptoms

Using nicotine replacement therapy (Patches)

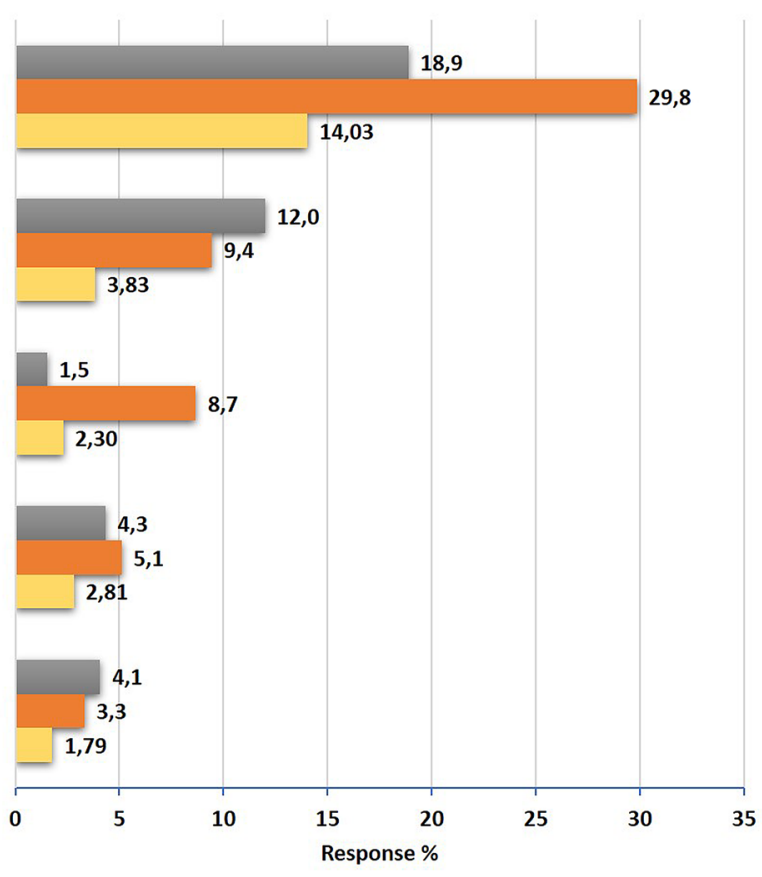

- Current smoker $\square$ Former smoker $\square$ Never smoker

Fig. 2 Methods used by the participants to control any experienced E-cig withdrawal symptoms during fasting time in Ramadan $(\mathrm{n}=392)$

smokers with no quitting experience [32]. In addition, the use of E-cig took different patterns, starting with dual-use with tobacco cigarettes, E-cig use by non-smokers, and some smokers switched from tobacco to exclusive use of E-cig [33].

E-cig can produce high levels of rapidly absorbed nicotine; thus, E-cig could produce or maintain physical nicotine dependence [7]. The findings of our study revealed a significant proportion of E-cig users did not experience any withdrawal symptoms during fasting time, whether physical or psychological. However, the rest of the participants were more obvious have suffered from various withdrawal symptoms. This includes intensive craving for smoking and difficulty of breathing. Intense craving is defined as an 


\section{Tried to Quit E-Cig during Ramadan ( $n=103$ )}

\section{Successfully Quit E-Cig ( $n=82$ )}
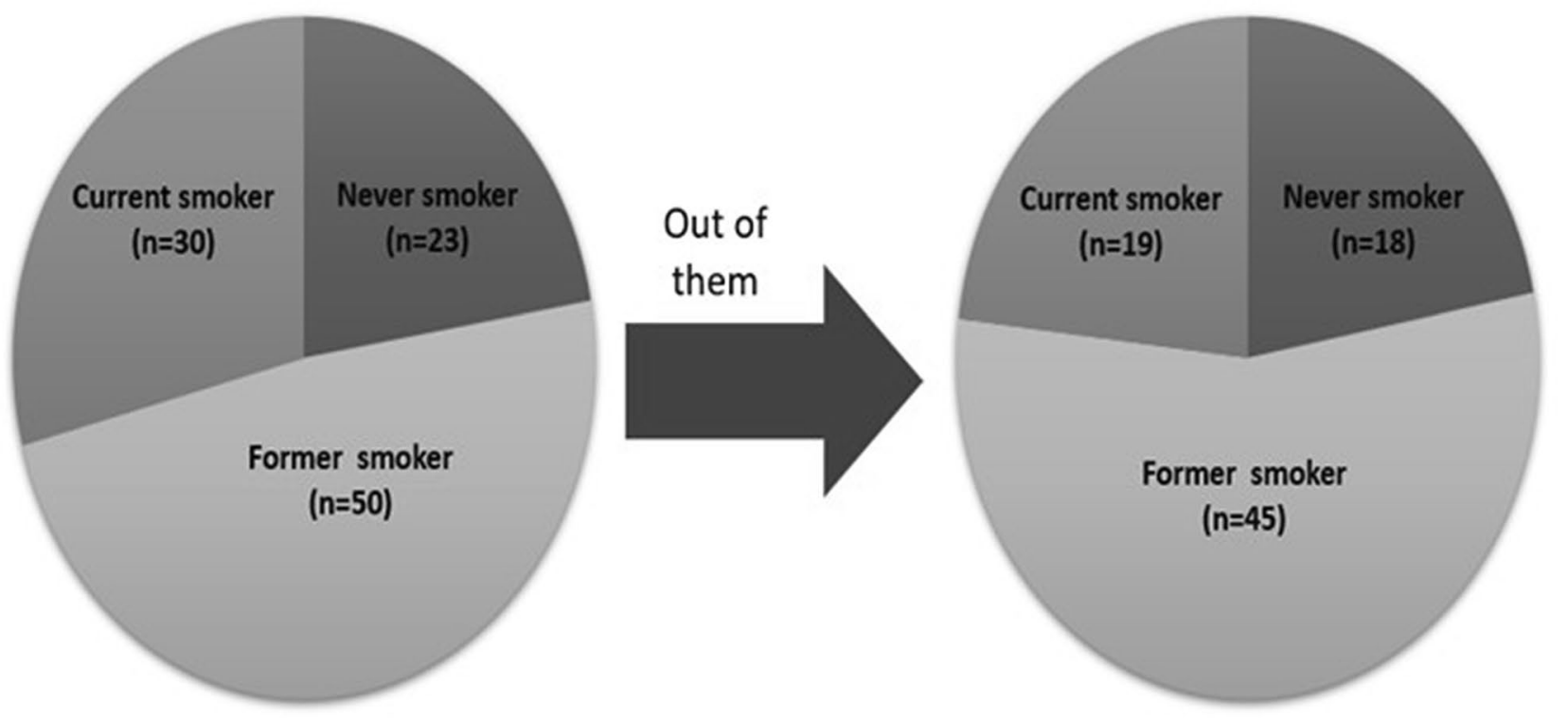

Fig. 3 Proportions of participants who tried to quit E-cig during the month of Ramadan $(\mathrm{n}=103)$ and those who successfully quitted E-cig $(\mathrm{n}=82)$

increased urge to smoke upon quitting or abstinence [34, 35]. Intensive craving sensation is one of the most important recidivism factors that circumscribe the success of E-cig quitting during fasting. A proportion of fasting E-cig users in our study complained of headache, dizziness, and nausea as physical withdrawal symptoms. Such symptoms could be also influenced by fasting itself, i.e. hypoglycemia and/ or caffeine withdrawal (among the overall cohort) as well as cigarette nicotine (among dual users) [36, 37]. Accordingly, more efforts should be invested in future studies to assess the severity of withdrawal symptoms apart from fasting to compare results. The addictive potentials of nicotine, regardless of the source, are well addressed in the literature. A study conducted by Talih et al. [38], found that higher nicotine concentrations in the E-liquid lead to higher nicotine yield by any E-cig. However, it is worth mentioning that the produced nicotine from E-cig is less than that of tobacco cigarettes [39].

The findings of our study shed the light on an important public health issue that needs more investigation within the UAE context. Using E-cig is becoming more popular worldwide, and the recent legalization of E-cig in the UAE could lead to an increasing E-cig use in the near future. The month of Ramadan offers a valuable chance for smokers to quit, however, this requires mindfulness and mature investment of these moments. Future studies are needed to examine the severity of withdrawal symptoms during fasting and apart from fasting using nationally representative samples. Our study comes with limitations that should be taken into consideration when interpreting our results. First, the convenience sampling approach could potentially affect the representativeness of our sample and the generalizability of results to all E-cig users in the UAE.

We believed that this was the most feasible sampling approach as we did not have a sampling frame from previous data on the same topic within the UAE; thus, random sampling was not applicable. Second, our survey questionnaire was administered electronically (web-based) due to the COVID-19 pandemic crisis and lockdown during the period of our data collection. Hence, only E-cig users who use the internet and social media platforms were able to participate. Third, the questionnaire represented selfreported data that may have been exposed to recall bias. Fourth, we have not assessed other forms of tobacco use which are quite popular in the UAE to limit the length of our questionnaire as excessive web-based surveys were launched about COVID-19 studies and many people would avoid participating in lengthy questionnaires, and lastly, withdrawal symptoms could have been influenced by the process of fasting itself among all participants as well as by cigarettes nicotine among dual users. Nevertheless, our study has provided baseline data about E-cig use among current users in the UAE population and this could help to improve the understanding of the pattern of smoking in the country and encourage further studies on this emerging topic in the UAE. 


\section{Conclusion}

E-cig use is gaining popularity within the UAE after the recent legalization. Despite the controversy about the safety and effectiveness of E-cig in global literature, these devices are being adopted by users due to their potential of smoking cessation/reduction among tobacco smokers as commonly advertised and promoted by manufacturers and some research. Also, intermittent fasting (e.g., Ramadan time) could provide an avenue to train oneself on abstinence from nicotine. However, this needs a high level of awareness and willingness among users of E-cig. Moreover, the effectiveness of E-cig in aiding smoking cessation should be investigated with more robust data and a higher level of evidence, especially in a new context of usage as the UAE, considering various types of devices and hundreds of E-liquid brands, and the influence of concurrent poly-tobacco use.

Acknowledgements The authors would like to thank all the study participants. Also, ABA is currently supported by the Tempus Public Foundation's Scholarship at the University of Debrecen.

Author Contributions Conceptualization: MB, FJ; Methodology: MB, FJ, ABA, RA,YA, ZK, HA; Formal analysis: MB; Writing-original draft preparation: $\mathrm{MB}, \mathrm{FJ}, \mathrm{ABA}, \mathrm{RA}, \mathrm{YA}, \mathrm{ZK}, \mathrm{HA} ;$ Writing-review and editing: $\mathrm{MB}, \mathrm{FJ}, \mathrm{ABA}$. All authors have read and agreed on the submitted version of the manuscript.

Funding This research project did not receive any specific grant from funding agencies in the public, commercial, or not-for-profit sectors.

Availability of Data The dataset generated and analyzed in this study is available from the corresponding author on a reasonable request.

\section{Compliance with Ethical Standards}

Conflict of interest The authors have no conflicts of interest to declare that are relevant to the content of this article.

Ethical Approval Ethical approval for our study was obtained from the Research Ethics Committee, University of Sharjah (Approval number: REC-20-07-30-01).

Consent to Participate All participants have provided a written informed consent electronically.

\section{References}

1. World Health Organization. (2020). Tobacco fact sheet. Retrieved December 10, 2020, from https://www.who.int/news-room/factsheets/detail/tobacco.

2. Tobacco, G. B. D. (2017). Smoking prevalence and attributable disease burden in 195 countries and territories, 1990-2015: A systematic analysis from the Global Burden of Disease Study 2015. Lancet, 389(10082), 1885-1906. https://doi.org/10.1016/S0140 $-6736(17) 30819-X$.
3. World Health Organization. (2019). WHO global report on trends in prevalence of tobacco use 2000-2025 (Third.). Geneva: World Health Organization. Retrieved from https:// www.who.int/publications/i/item/who-global-report-on-trend s-in-prevalence-of-tobacco-use-2000-2025-third-edition.

4. Maziak, W., Taleb, Z. B., Bahelah, R., Islam, F., Jaber, R., Auf, R., \& Salloum, R. G. (2015). The global epidemiology of waterpipe smoking. Tobacco Control, 24 Suppl 1(Suppl 1), i3-i12. https://doi.org/10.1136/tobaccocontrol-2014-051903.

5. Noël, A., Verret, C. M., Hasan, F., Lomnicki, S., Morse, J., Robichaud, A., \& Penn, A. L. (2018). Generation of electronic cigarette aerosol by a third-generation machine-vaping device: Application to toxicological studies. Journal of Visualized Experiments: JoVE, 138, e58095. https://doi.org/10.3791/58095

6. National Academies of Sciences Medicine and Engineering. (2018). Public Health Consequences of E-Cigarettes. Washington, DC: National Academies Press.

7. Centers for Disease Control and Prevention. (2010). How tobacco smoke causes disease: The biology and behavioral basis for smoking-attributable disease: A report of the surgeon general. Atlanta, GA: US Government Printing Office.

8. Kaur, G., Pinkston, R., Mclemore, B., Dorsey, W. C., \& Batra, S. (2018). Immunological and toxicological risk assessment of e-cigarettes. European Respiratory Review, 27(147), 170119. https://doi.org/10.1183/16000617.0119-2017.

9. World Medical Association. (2017). WMA statement on electronic cigarettes and other electronic nicotine delivery systems. Retrieved December 10, 2020, from https://www.wma.net/polic ies-post/wma-statement-on-electronic-cigarettes-and-other-elect ronic-nicotine-delivery-systems/.

10. Adriaens, K., Van Gucht, D., \& Baeyens, F. (2018). IQOS(TM) vs. e-cigarette vs. tobacco cigarette: A direct comparison of short-term effects after overnight-abstinence. International Journal of Environmental Research and Public Health. https:// doi.org/10.3390/ijerph15122902.

11. Cleveland Clinic Abu Dhabi. (2018). Why Ramadan is the ideal time to quit smoking? Retrieved December 10, 2020, from https ://www.clevelandclinicabudhabi.ae/en/health-byte/pages/whyramadan-is-the-ideal-time-to-quit-smoking.aspx.

12. Hamad Medical Corporation. (2019). Quit Smoking during Ramadan. Retrieved December 10, 2020, from https://www. hamad.qa/EN/yourhealth/RamadanHealth/HealthInformation/ Pages/Quit-Smoking.aspx

13. Khoudigian, S., Devji, T., Lytvyn, L., Campbell, K., Hopkins, R., \& O'Reilly, D. (2016). The efficacy and short-term effects of electronic cigarettes as a method for smoking cessation: A systematic review and a meta-analysis. International Journal of Public Health, 61(2), 257-267. https://doi.org/10.1007/s0003 8-016-0786-z.

14. Hua, M., Alfi, M., \& Talbot, P. (2013). Health-related effects reported by electronic cigarette users in online forums. Journal of Medical Internet Research, 15(4), e59. https://doi. org/10.2196/jmir.2324.

15. UAE Government Portal. (2020). Fact Sheet about UAE. Retrieved December 10, 2020, from https://u.ae/en/about-theuae/fact-sheet.

16. World Health Organization. (2019). WHO report on the global tobacco epidemic. Retrieved December 10, 2020, from http://158.232.12.119/tobacco/surveillance/policy/country_profi le/are.pdf.

17. Al-Houqani, M., Ali, R., \& Hajat, C. (2012). Tobacco smoking using Midwakh is an emerging health problem-evidence from a large cross-sectional survey in the United Arab Emirates. PLoS ONE, 7(6), e39189. https://doi.org/10.1371/journal.pone.00391 89. 
18. UAE Government Portal. (2019). Tobacco and alcohol provisions. Retrieved December 10, 2020, from https://u.ae/en/informatio $\mathrm{n}$-and-services/health-and-fitness/tobacco-and-alcohol-provisions.

19. Centers for Disease Control and Prevention. (2020). Smoking and tobacco use-fast facts. Retrieved December 10, 2020, from https:// www.cdc.gov/tobacco/data_statistics/fact_sheets/fast_facts/index .htm.

20. Boyle, P., Gandini, S., Robertson, C., Zatonski, W., Fagerstrom, K., Slama, K., et al. (2000). Characteristics of smokers' attitudes towards stopping: Survey of 10,295 smokers in representative samples from 17 European countries. European Journal of Public Health, 10(suppl_3), 5-14. https://doi.org/10.1093/eurpub/10. suppl_3.5.

21. Manis, M., Tamm, M., \& Stolz, D. (2018). Unaided smoking cessation in healthy employees. Respiration, 95(2), 80-86. https:// doi.org/10.1159/000481826.

22. Cahill, K., Stevens, S., Perera, R., \& Lancaster, T. (2013). Pharmacological interventions for smoking cessation: An overview and network meta-analysis. The Cochrane Database of Systematic Reviews, 5, CD009329. https://doi.org/10.1002/14651858.CD009 329.pub2.

23. Wu, P., Wilson, K., Dimoulas, P., \& Mills, E. J. (2006). Effectiveness of smoking cessation therapies: A systematic review and meta-analysis. BMC Public Health, 6, 300. https://doi. org/10.1186/1471-2458-6-300.

24. Crotty Alexander, L. E., Drummond, C. A., Hepokoski, M., Mathew, D., Moshensky, A., Willeford, A., et al. (2018). Chronic inhalation of e-cigarette vapor containing nicotine disrupts airway barrier function and induces systemic inflammation and multiorgan fibrosis in mice. American Journal of Physiology. Regulatory, Integrative and Comparative Physiology, 314(6), R834-R847. https://doi.org/10.1152/ajpregu.00270.2017.

25. Al-Houqani, M., \& Hajat, C. (2011). Tobacco smoking among UAE nationals. Chest, 140, 438A. https://doi.org/10.1378/chest .1108566.

26. Moh'd Al-Mulla, A., Abdou Helmy, S., Al-Lawati, J., Al Nasser, S., Ali Abdel Rahman, S., Almutawa, A., et al. (2008). Prevalence of tobacco use among students aged 13-15 years in Health Ministers' Council/Gulf Cooperation Council Member States, 2001-2004. Journal of School Health, 78(6), 337-343. https:// doi.org/10.1111/j.1746-1561.2008.00311.x.

27. Adolfo, A. B., AhnAllen, C. G., \& Tidey, J. W. (2009). Effects of smoking cues on caffeine urges in heavy smokers and caffeine consumers with and without schizophrenia. Schizophrenia Research, 107(2-3), 192-197. https://doi.org/10.1016/j.schre s.2008.10.009.

28. Emurian, H. H., Nellis, M. J., Brady, J. V., \& Ray, R. L. (1982). Event time-series relationship between cigarette smoking and coffee drinking. Addictive Behaviors, 7(4), 441-444. https://doi. org/10.1016/0306-4603(82)90016-8.

29. World Health Organization. (2017). WHO Report on the Global Tobacco Epidemic 2017 : Monitoring tobacco use and prevention policies. Retrieved December 10, 2020, from https://www.who. int/tobacco/global_report/2017/en/.

30. Dwedar, I., Ruby, D., \& Mostafa, A. (2019). A survey exploring knowledge and beliefs about electronic cigarettes between health care providers and the general population in Egypt. International Journal of Chronic Obstructive Pulmonary Disease, 14, 19431950. https://doi.org/10.2147/COPD.S214389.

31. Tamimi, N. (2018). Knowledge, attitudes and beliefs towards e-cigarettes among e-cigarette users and stop smoking advisors in South East England: A qualitative study. Primary Health Care Research \& Development, 19(2), 189-196. https://doi. org/10.1017/S1463423617000445.

32. Wang, X., Zhang, X., Xu, X., \& Gao, Y. (2019). Perceptions and use of electronic cigarettes among young adults in China. Tobacco Induced Diseases, 17, 17. https://doi.org/10.18332/tid/102788.

33. Delnevo, C. D., Giovenco, D. P., Steinberg, M. B., Villanti, A. C., Pearson, J. L., Niaura, R. S., \& Abrams, D. B. (2016). Patterns of electronic cigarette use among adults in the United States. Nicotine \& Tobacco Research, 18(5), 715-719. https://doi. org/10.1093/ntr/ntv237.

34. Allen, S. S., Bade, T., Hatsukami, D., \& Center, B. (2008). Craving, withdrawal, and smoking urges on days immediately prior to smoking relapse. Nicotine \& Tobacco Research: Official Journal of the Society for Research on Nicotine and Tobacco, 10(1), 35-45. https://doi.org/10.1080/14622200701705076.

35. Jiloha, R. C. (2014). Pharmacotherapy of smoking cessation. Indian Journal of Psychiatry, 56(1), 87-95. https://doi. org/10.4103/0019-5545.124726.

36. Awada, A., \& Al Jumah, M. (1999). The first-of-Ramadan headache. Headache, 39(7), 490-493. https://doi.org/10.104 6/j.1526-4610.1999.3907490.x.

37. Siaw, M. Y. L., Chew, D. E. K., Dalan, R., Abdul Shakoor, S. A. K. K., Othman, N., Choo, C. H., et al. (2014). Evaluating the effect of ramadan fasting on muslim patients with diabetes in relation to use of medication and lifestyle patterns: A prospective study. International Journal of Endocrinology, 2014, 308546. https://doi.org/10.1155/2014/308546.

38. Talih, S., Balhas, Z., Eissenberg, T., Salman, R., Karaoghlanian, N., El Hellani, A., et al. (2015). Effects of user puff topography, device voltage, and liquid nicotine concentration on electronic cigarette nicotine yield: Measurements and model predictions. Nicotine \& Tobacco Research, 17(2), 150-157. https://doi. org/10.1093/ntr/ntu174.

39. Adamson, J., Thorne, D., Zainuddin, B., Baxter, A., McAughey, J., \& Gaça, M. (2016). Application of dosimetry tools for the assessment of e-cigarette aerosol and cigarette smoke generated on two different in vitro exposure systems. Chemistry Central Journal, 10, 74. https://doi.org/10.1186/s13065-016-0221-9.

Publisher's Note Springer Nature remains neutral with regard to jurisdictional claims in published maps and institutional affiliations. 